\title{
A Study of QTc Prolongation as a Screening Tool for Cardiovascular Disease in Type 2 Diabetes Patients of Karad, India
}

\author{
Sanjay Tukaram Thorat ${ }^{1}$, Parikshit Gajanan Mankar², Niyati Kaila³ , Avanti Jaywant Damle ${ }^{4}$, \\ Radhika Ratanlal Bajaj ${ }^{5}$, Vaibhav Vijay Rane ${ }^{6}$ \\ 1, 2, 3, 4, 5, 6 Department of Medicine, Krishna Institute of Medical Sciences \\ Deemed to be University, Karad, Maharashtra, India.
}

\section{ABSTRACT}

\section{BACKGROUND}

The occurrence of QT interval prolongation is higher in subjects with type 2 diabetes mellitus (T2DM). Duration of QT interval corrected (QTc) for heart rate is independently related with severity of cardiovascular diseases in diabetics. This study was proposed to assess the QTc prolongation as a diagnostic tool for cardiovascular disease in T2DM patients.

\section{METHODS}

This study included 100 diabetic patients admitted in wards of a tertiary care center. A thorough clinical examination was carried out for all the patients. Patients were investigated for the fasting blood glucose level, glycated haemoglobin (HbA1c), lipid profile \& electrocardiogram (ECG). Data was represented as percentage. Mean and standard deviation (SD) of quantitative variables were tabulated, $\mathrm{t}$ test was used for correlation and receiver operating characteristic (ROC) curve was used for evaluating area under curve. $\mathrm{P}<0.05$ was considered statistically significant.

\section{RESULTS}

Male preponderance was observed. All the study subjects had a prolonged period of diabetes with various metabolic complications. The area under the curve estimation of QTc > 400 ms with respect to HbA1c and duration of diabetes showed significant correlation between longer duration of diabetes and raised HbA1c associated with raised QTc interval $(\mathrm{P}<0.05)$.

\section{CONCLUSIONS}

Diagnosis of prolonged QTc interval could be utilized for estimating cardiovascular risk in diabetes patients. It can be easily assessed on ECG besides being a noninvasive investigation which is also affordable in evaluating the cardiovascular risk in T2DM patients.

\section{KEY WORDS}

Blood Glucose, Cardiovascular Diseases, Electrocardiography, Glycated Haemoglobin A, Long QT Syndrome, Type 2 Diabetes Mellitus
Corresponding Author: Dr Parikshit Gajanan Mankar, Department of Medicine, Krishna Institute of Medical Sciences Deemed to be University, Karad, Maharashtra, India. E-mail: mankarparig@gmail.com

DOI: $10.14260 /$ jemds/2021/598

How to Cite This Article:

Thorat ST, Mankar PG. Kaila N, et al. A study of QTC prolongation as a screening tool for cardiovascular disease in type 2 diabetes patients of Karad, India. J Evolution Med Dent Sci 2021;10(34):29342938, DOI: $10.14260 /$ jemds/2021/598

Submission 10-03-2021,

Peer Review 13-07-2021,

Acceptance 21-07-2021,

Published 23-08-2021.

Copyright (C) 2021 Sanjay Tukaram Thorat et al. This is an open access article distributed under Creative Commons Attribution License [Attribution 4.0 International (CC BY 4.0)] 


\section{BACKGROUND}

The global prevalence of all the leading chronic diseases is increasing, with the greatest burden occurring in developing countries, and this is projected to increase substantially over the next two decades. Indeed, cardiovascular disease is already the leading cause of mortality in some developing countries. Projections for the next two decades include nearly a tripling of ischemic heart disease and stroke mortality in patients of diabetes. ${ }^{1,2}$

Diabetes mellitus (DM) has routinely been described as a metabolic disorder characterized by hyperglycaemia that develops as a consequence of defects in insulin secretion, insulin action, or both. Type 2 diabetes encompasses individuals who have insulin resistance (IR) and usually relative (rather than absolute) insulin deficiency. ${ }^{3}$

The global number of individuals with diabetes in 2000 was estimated to be 171 million ( $2.8 \%$ of the world's population), a figure projected to increase in 2030 to 366 million (6.5\%), 298 million of whom will live in developing countries. $^{2}$ Overweight and obesity are increasing dramatically and contribute to the burden of diabetes and other chronic health conditions. Indeed, the modern environment promotes behaviours that cause obesity. ${ }^{4}$

In India, there are about 69.2 million people with diabetes and are expected to cross 123.5 million by $2040 . .^{5}$ Several landmark studies such as the United Kingdom Prospective Diabetes Study (UKPDS) have demonstrated that strict glycaemic control does limit microvascular disease while attempts to improve macrovascular outcomes through glucose-lowering interventions still remain shrouded with controversy. A relative risk (RR) reduction in myocardial infarction $(\mathrm{MI})(\mathrm{P}=0.052)$ has been observed in the 10 years of post-trial follow-up of UKPDS. 6

The QT interval reflects the total duration of ventricular myocardial depolarization and repolarization: a prolonged QT interval is associated with sudden death and poor survival in apparently healthy subjects. ${ }^{7}$

The relation of QT interval prolongation with diabetes complications, poor survival prognosis and sudden death has recently received considerable interest. It has been postulated that QT prolongation accounts for higher mortality in people with diabetes and its complications as the prevalence of QT interval prolongation is higher among patients with diabetes mellitus, ${ }^{8}$ ischaemic heart disease (IHD). ${ }^{9}$ end stage renal disease ${ }^{10}$ and autonomic neuropathy. ${ }^{11}$

The QT interval on the electrocardiogram (ECG) reflects the depolarization and repolarization time of the left ventricular myocardium. ${ }^{12}$ Previous studies have shown that patients with prolongation of the QT interval, either congenital or acquired, often experience episodes of sudden death due to malignant ventricular arrhythmias. ${ }^{13}$

A previous study showed that the duration of the QT interval corrected for heart rate (QTc) is significantly and independently related with the existence and severity of cardiovascular diseases in diabetics. ${ }^{14}$

We conducted this study to evaluate the QTc prolongation as a screening tool for cardiovascular disease in type 2 diabetes mellitus patients.

\section{METHODS}

This is an analytical cross-sectional study. Total 100 diabetic patients visiting Medicine out-patient department (OPD) and admitted in wards of KIMS DU, Karad, Maharashtra from September 2019 to August 2020 were included in the study. Complete history taking and clinical examination of all the patients was done, they were investigated for the fasting blood glucose level, HbA1c, lipid profile \& ECG.

\section{Ethical Clearance}

Ethical clearance was obtained from the Institutional Ethics Committee. All the patients signed a written informed consent before participating in the study.

\section{Inclusion Criteria}

- Patients of age $\geq 18$ years, both males and females

- Patients diagnosed with type 2 diabetes mellitus

\section{Exclusion Criteria}

- Patients with type-1 DM

- Hypothyroidism

- Patients already on lipid lowering drugs.

- Pregnant females with gestational diabetes mellitus (GDM).

- Hypertensive patients using beta blockers or thiazide diuretics.

- Electrolyte abnormalities.

- Patients with ischaemic heart disease.

- Other disease conditions where lipid profile is altered due to pathophysiologic conditions or drugs.

\section{Sample Size Calculation}

According to a study conducted by M Wahane et al. the proportion of QTc prolongation seen in diabetic patients was $33 \% 15$

So, $\mathrm{p}=33 \%$

Using formula for sample size (n) calculation,

$n=4 \times p \times q$

$\mathrm{e}^{2}$

Where, $\mathrm{p}=33 \%=0.33$

$\mathrm{q}=1-\mathrm{p}=0.67$

Taking e, absolute error of $10 \%, \mathrm{e}=0.1$

So, $\mathrm{n}=4 \times 0.33 \times 0.67$

$0.1 \times 0.1$

$\mathrm{n}=88.44 \approx 89$

A minimum of 89 patients were included in the study, rounding it up to 100 .

Sample size $=\mathrm{n}=100$.

So, a total of 100 patients will be included in the study.

\section{Method of Data Collection}

Five consecutive beats were considered on lead V5. The QT interval was taken from the beginning of the QRS complex to the end of the downslope of the $\mathrm{T}$ wave (crossing of the isoelectric line). Two observers measured all the intervals and the QTc for each subject was taken as the mean value of 
the five calculated intervals and the mean of the reading of the two observers to minimize inter-observer variability as proposed previously. ${ }^{12}$ QTc greater than $0.4 \mathrm{~s}$ was considered abnormally prolonged, in accordance with the criteria commonly used in the literature.

\section{Statistical Analysis}

A pre-designed pre-tested questionnaire was used to collect the data. Data collected was entered in Microsoft Excel. Data was represented in frequencies and percentages. Mean and standard deviation of quantitative variables is shown. ROC curve for area under the curve and test for correlation [specify the tests] were applied using EpiInfo version 7.2 and Statistical Package for Social Sciences (SPSS software version 20) for analysis. Student's t test was used for correlation and ROC curve was used for evaluating area under curve. RR and QT intervals were measured with a ruler on the resting ECG tracing which was available for 3147.

\section{RESULTS}

\begin{tabular}{|c|c|c|c|}
\hline Age Group & $\begin{array}{c}\text { Gender } \\
\text { Females Provide Both } \\
\text { Number and Percentage }\end{array}$ & Males & Total \\
\hline $\mathrm{A}<40$ & $0(0 \%)$ & $3(4.55 \%)$ & $3(3 \%)$ \\
\hline B $40-50$ & $6(17.65 \%)$ & $12(18.18 \%)$ & $18(18 \%)$ \\
\hline C 51 to 60 & $9(26.47 \%)$ & $20(30.30 \%)$ & 29 (29\%) \\
\hline D 61 to 70 & $15(44.12 \%)$ & $17(25.765)$ & 32 (32\%) \\
\hline$E>70$ & $4(11.76 \%)$ & $14(21.21 \%)$ & 18 (18\%) \\
\hline Total & $34(100 \%)$ & $66(100 \%)$ & $100(100 \%)$ \\
\hline Mean & $62.53 \pm 10.10$ & $60.38 \pm 12.56$ & $61.11 \pm 11.77$ \\
\hline \multicolumn{4}{|c|}{ Table 1. Age \& Gender Distribution } \\
\hline
\end{tabular}

There were 34 females (34\%) and 66 males (66\%) in our study. With a male to female ratio of $1.94: 1$. We saw male majority in our study. Majority of the patients were from the age group of 61 to 70 years (32\%) followed by 51 to 60 years (29\%). Mean age of our study participants was $61.11 \pm 11.77$ years, mean age of males $60.38 \pm 12.56$ years, was less than that of females $62.53 \pm 10.10$ years suggesting slight earlier presentation in males.

\begin{tabular}{|cc|ccc|}
\hline & Minimum & Maximum & Mean & $\begin{array}{c}\text { Standard } \\
\text { Deviation }\end{array}$ \\
Age & 25.0 & 87.0 & 61.11 & 11.77 \\
BSL (F) & 63.0 & 487.0 & 205.22 & 103.49 \\
HbA1c & 5.4 & 13.9 & 7.50 & 1.64 \\
HDL & 17.0 & 70.0 & 39.34 & 10.88 \\
LDL & 18.0 & 163.0 & 120.94 & 37.37 \\
TG & 50.0 & 378.0 & 136.60 & 53.61 \\
QTc & 360.0 & 497.0 & 424.50 & 29.43 \\
Duration of diabetes & 1.0 & 18.0 & 12.52 & 4.36 \\
\hline \multicolumn{5}{c}{ Table 2. Descriptive Statistics } \\
\hline
\end{tabular}

Mean fasting blood sugar level (BSL) of our study participants was $205.22 \pm 103.49$. Mean HbA1c of our study participants was $7.5 \pm 1.64$. Mean high density lipoproteins (HDL) was $39.34 \pm 10.88$, mean low density lipoprotein (LDL) was $120.94 \pm 37.37$, mean triglycerides $(\mathrm{TG})$ was $136.60 \pm$ 53.61 and mean QTc was $424.50 \pm 29.43$. Mean duration of diabetes was $12.52 \pm 4.36$ years.

The area under curve estimation of QTc $>400 \mathrm{~ms}$ with regards to HbA1c \& duration of diabetes showed significant correlation between the longer duration of diabetes (78\%) and raised $\mathrm{HbA1c}(72 \%)$ being associated with raised QTc interval $(\mathrm{P}<0.05)$.

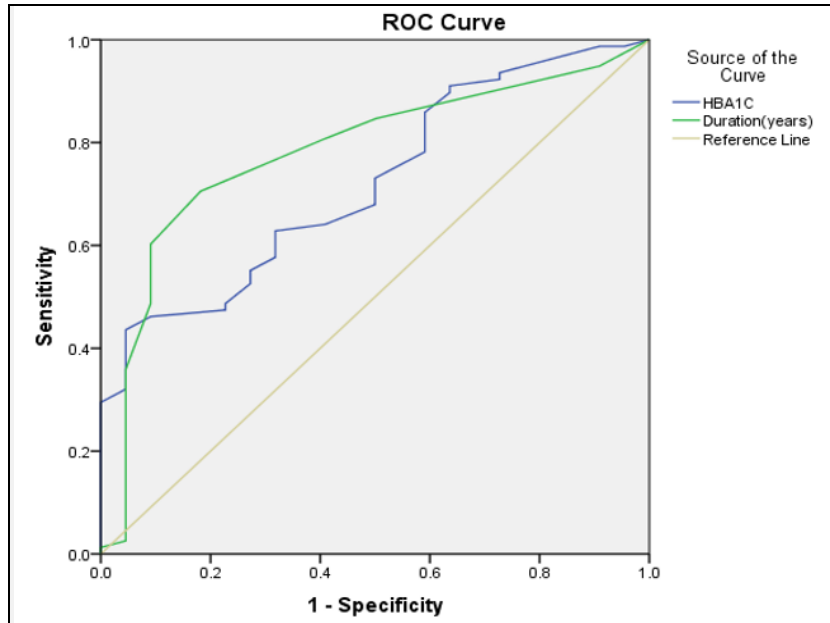

Diagonal segments are produced by ties.

Figure 1. ROC Curve HbA1c, Duration of Diabetes \& QT Prolongation

\begin{tabular}{|c|c|c|c|c|c|}
\hline \multirow{3}{*}{$\begin{array}{l}\text { Test Result } \\
\text { Variable (s) }\end{array}$} & \multirow{3}{*}{ Area } & \multicolumn{3}{|c|}{ Area Under the Curve } & \\
\hline & & \multirow{2}{*}{$\begin{array}{l}\text { Std. } \\
\text { Error }\end{array}$} & \multirow[t]{2}{*}{ P Value } & $\begin{array}{c}\text { Asymptotic } 95 \% \text { Confidence } \\
\text { Interval }\end{array}$ & \\
\hline & & & & Lower Bound & Upper Bound \\
\hline $\mathrm{HbA1c}$ & 0.721 & 0.056 & 0.002 & 0.611 & 0.832 \\
\hline $\begin{array}{c}\text { Duration } \\
\text { (years) }\end{array}$ & 0.782 & 0.054 & $<0.001$ & 0.676 & 0.889 \\
\hline
\end{tabular}

\begin{tabular}{|c|c|c|c|c|c|}
\hline Parameters & QTc Raised & $\mathbf{N}$ & Mean & $\begin{array}{c}\text { Std. } \\
\text { Deviation }\end{array}$ & P Value \\
\hline \multirow{2}{*}{ Age } & Yes & 78 & 60.82 & 11.89 & \multirow{2}{*}{0.646} \\
\hline & No & 22 & 62.14 & 11.57 & \\
\hline \multirow{2}{*}{ BSL(F) } & Yes & 78 & 214.23 & 107.33 & \multirow[b]{2}{*}{0.101} \\
\hline & No & 22 & 173.27 & 82.95 & \\
\hline \multirow{2}{*}{ HbA1c } & Yes & 78 & 7.76 & 1.73 & \multirow{2}{*}{0.002} \\
\hline & No & 22 & 6.57 & 0.78 & \\
\hline \multirow[b]{2}{*}{ HDL } & Yes & 78 & 35.97 & 10.85 & \multirow[b]{2}{*}{0.03} \\
\hline & No & 22 & 44.64 & 11.18 & \\
\hline \multirow{2}{*}{ LDL } & Yes & 78 & 77.44 & 37.30 & \multirow{2}{*}{0.023} \\
\hline & No & 22 & 57.00 & 33.79 & \\
\hline \multirow[b]{2}{*}{ TG } & Yes & 78 & 130.27 & 55.66 & \multirow{2}{*}{0.204} \\
\hline & No & 22 & 113.77 & 44.41 & \\
\hline \multirow{2}{*}{$\begin{array}{c}\text { Duration of } \\
\text { diabetes (years) }\end{array}$} & Yes & 78 & 6.73 & 3.79 & \multirow{2}{*}{0.001} \\
\hline & No & 22 & 3.59 & 3.14 & \\
\hline \multicolumn{6}{|c|}{$\begin{array}{l}\text { Table 4. Correlation between Cases with } \\
\text { Raised QTc \& Study Parameters }\end{array}$} \\
\hline
\end{tabular}

When we compared the study parameters in relation to patients with raised QTc (78\%) and normal QTc (22\%), we got significant difference in HbA1c, HDL, LDL \& duration of diabetes $(\mathrm{P}<0.05)$. Mean age of patients with raised QTc was $60.82 \pm 11.89$, and in patients with normal QTc it was $62.14 \pm$ 11.57. There was no statistical difference $(\mathrm{P}=0.646)$.

Mean fasting BSL of patients with raised QTc was 214.23 \pm 107.33 , and in patients with normal QTc it was $173.27 \pm$ 82.95. There was no any statistical difference $(P=0.101)$, but the mean fasting sugar levels of patients with raised QTc was higher. Mean HbA1c of patients with raised QTc was $7.76 \pm$ 1.73 , and in patients with normal QTc it was $6.57 \pm 11.18$. There was significant statistical difference $(P=0.002)$, and the mean HbA1c levels of patients with raised QTc was higher. Mean HDL of patients with raised QTc was $35.97 \pm$ 10.85 , and in patients with normal QTc it was $44.64 \pm 0.78$. There was significant statistical difference $(P=0.03)$, and the mean HDL levels of patients with raised QTc was lower. Mean LDL of patients with raised QTc was 77.44 \pm 37.30 , and in patients with normal QTc it was $57.00 \pm 33.79$. There was significant statistical difference $(P=0.023)$, and the mean LDL levels of patients with raised QTc was higher. 
Mean TG of patients with raised QTc was $130.27 \pm 55.66$, and in patients with normal QTc it was $113.77 \pm 44.41$. There was no any statistical difference $(\mathrm{P}=0.204)$, but the mean TG levels of patients with raised QTc was higher. Mean duration of diabetes of patients with raised QTc was $6.73 \pm 3.79$, and in patients with normal QTc it was $3.59 \pm 3.14$. There was significant statistical difference $(P=0.001)$, and the mean duration of diabetes of patients with raised QTc was higher.

\section{DISCUSSION}

Prolongation of QTc increases morbidity and mortality and QTc has been found to be longer in patients with DM than in healthy individuals. QT prolongation has been shown to predict cardiac death in type $2 \mathrm{DM}$. Although there is general agreement that the QT interval is affected by cardiac ischemia, the effect of hyperglycaemia on QT measures is controversial. Several studies suggest that assessing the QT interval could be a cost-effective way of stratifying such patients according to cardiovascular risk so that aggressive treatment could be directed appropriately to improve outcome.16 Prolonged QTc is an independent marker for chronic heart disease (CHD) risk in type 2 diabetes ${ }^{17}$ and has been demonstrated to be a highly significant predictor of cardiac death, even in newly diagnosed type 2 diabetes. ${ }^{18}$

There were 34 females (34\%) and 66 males (66\%) in our study. With a male to female ratio of $1.94: 1$. We saw male majority in our study. Majority of the patients were from the age group of 61 to 70 years (62\%) followed by 51 to 60 years (29\%). Mean age of our study participants was $61.11 \pm 11.77$ years, mean age of males $60.38 \pm 12.56$ years, was less than that of females $62.53 \pm 10.10$ years suggesting slight earlier presentation in males. Kumar R et al. ${ }^{16}$ observed that mean age for males was $51.3 \pm 10.1$ years and for females it was $53.8 \pm 12.1$ years, findings showed that females were affected at a later age similar to our study. Their age groups were lower than our study.

Mean BSL of our study participants was $205.22 \pm 103.49$. Mean HbA1c of our study participants was $7.5 \pm 1.64$. Mean HDL was $39.34 \pm 10.88$, mean LDL was $120.94 \pm 37.37$, mean TG was $136.60 \pm 53.61$ and mean QTc was $424.50 \pm 29.43$. Mean duration of diabetes was $12.52 \pm 4.36$ years. Kumar R et al. ${ }^{16}$ observed that mean duration of diabetes was $6.2 \pm 6$ years, mean TG was $233.3 \pm 147.5$, mean HDL was $37.9 \pm$ 11.4. Mean QTc was $419.8 \mathrm{~ms}$, similar to our study.

The area under curve estimation of QTc $>400 \mathrm{~ms}$ with regards to HbA1c \& duration of diabetes showed significant correlation between the longer duration of diabetes (78\%) and raised $\mathrm{HbA1c}(72 \%)$ being associated with raised QTc interval $(\mathrm{P}<0.05)$. JM Dekker et al. ${ }^{19}$ observed that QTc was significantly associated with fasting glucose, insulin, Cpeptide and glucose levels 60 and $120 \mathrm{~min}$ after an oral glucose load. For fasting C-peptide and the area under the glucose curve (AUGC). The results of the study by Kumar R et al. ${ }^{16}$ reveal the significant involvement of HOMA-IR, age and HbA1c on the QTc interval, whereas diabetes duration and body mass index (BMI) were not significant when correlated with the length of the QTc interval which is not in accordance with our study. When we compared the study parameters in relation to patients with raised QTc (78 \%) and normal QTc
(22\%), we got significant difference in HbA1c, HDL, LDL \& duration of diabetes $(\mathrm{P}<0.05)$. Cardoso CR et al. ${ }^{20}$ observed significant difference between the HbA1c \& duration of diabetes in patients with raised QTc as compared to normal QTc.

Mean HDL of patients with raised QTc was $35.97 \pm 10.85$, and in patients with normal QTc it was $44.64 \pm 0.78$. There was significant statistical difference $(P=0.03)$, and the mean HDL levels of patients with raised QTc was lower. Mean LDL of patients with raised QTc was 77.44 \pm 37.30 , and in patients with normal QTc it was $57.00 \pm 33.79$. There was significant statistical difference $(P=0.023)$, and the mean LDL levels of patients with raised QTc was higher. Mean TG of patients with raised QTc was $130.27 \pm 55.66$, and in patients with normal QTc it was $113.77 \pm 44.41$. There was no any statistical difference $(P=0.204)$, but the mean TG levels of patients with raised QTc was higher. Timar R et al. ${ }^{21}$ observed a strong correlation between the deranged lipids and prolonged QTc interval in patients of diabetes which is similar to our study.

Deranged lipids are one of the most important risk factors for cardiovascular disease in diabetes patients. Kannel WB et al. ${ }^{22}$ reported that deranged lipids and the incidence of cardiovascular disease are higher in diabetic patients. Porez G et al. ${ }^{23}$ reported that treatment of dyslipidaemia improves the cardiac morbidity, and prevents any cardiovascular complications. Our study proves that the raised QTc interval is associated with increased HbA1c \& long duration of diabetes and the lipid profile is deranged in these patients. All these factors altogether and individually are risk factors for cardiovascular disease in diabetic patients.

\section{CONCLUSIONS}

We conclude that prolonged QTc interval can be used as a screening tool for estimating cardiovascular risk in diabetes patients. It can be easily assessed on ECG and is a noninvasive investigation of very low cost. Prevention of cardiovascular diseases in type 2 diabetes patients is a challenge for today's physicians. Watching for prolonged QTc interval which can be easily assessed on ECG is thus helpful in evaluating the cardiovascular risk in diabetes patients. Our study thus recommends the use of prolonged QTc interval as a screening tool for evaluating cardiovascular risk in diabetes patients.

Data sharing statement provided by the authors is available with the full text of this article at jemds.com.

Financial or other competing interests: None.

Disclosure forms provided by the authors are available with the full text of this article at jemds.com.

\section{REFERENCES}

[1] Yach D, Hawkes C, Gould CL, et al. The global burden of chronic diseases: overcoming impediments to prevention and control. JAMA 2004;291(21):2616-22.

[2] Wild S, Roglic G, Green A, et al. Global prevalence of diabetes: estimates for 2000 and projections for 2030. Diabetes Care 2004;27(5):1047-53. 
[3] Standards of Medical Care in Diabetes-2016: Summary of Revisions. Diabetes Care 2016;(39 Suppl 1):S4-5.

[4] Young LR, Nestle M. The contribution of expanding portion sizes to the US obesity epidemic. Am J Public Health 2002;92(2):246-9.

[5] International Diabetes Federation. IDF Atlas. 7th edn. 2020. [Last accessed on 2020 Sept 7].

[6] Holman RR, Paul SK, Bethel MA, et al. 10-year follow-up of intensive glucose control in type 2 diabetes. Engl J Med 2008;359(15):1577-89.

[7] Schouten EG, Dekker JM, Meppelimk P, et al. QT interval prolongation predicts cardiovascular mortality in an apparently healthy population. Circulation 1991;84(4):1516-23.

[8] Sivieri R, Veglio M, Chinaglia A, et al. Prevalence of QT prolongation in diabetic population and its association with autonomic neuropathy. The Neuropathy Study Group of the Italian Society for the Study of Diabetes. Diabetic Medicine 1993;10(10):920-4.

[9] Møller M. QT interval in relation to ventricular arrhythmias and sudden cardiac death in postmyocardial infarction patients. Acta Medica Scandinavica 1981;210(1-6):73-7.

[10] Sawicki PT, Dähne R, Bender R, et al. Prolonged QT interval as a predictor of mortality in diabetic nephropathy. Diabetologia 1996;39(1):77-81.

[11] Jermendy G, Koltai MZ, Pogatsa G. QT prolongation in type 2 (non-insulin-dependent) diabetic patients with cardiac autonomic neuropathy. Acta Diabetol 1990;27(4):295-301.

[12] Bednar MM, Harrigan EP, Anziano RJ, et al. The QT interval. Prog Cardiovasc Dis 2001;43(5 Suppl 1):1-45.

[13] Wolk R, Stec S, Kulakowski P. Extrasystolic beats affect transmural electrical dispersion during programmed electrical stimulation. Eur J Clin Invest 2001;31(4):293301.

[14] Tentolouris N, Katsilambros N, Papazachos G, et al. Corrected QT interval in relation to the severity of the diabetic autonomic neuropathy. Eur J Clin Invest 1997;27(12):1049-54.

[15] Wahane M, Gupta A, Tyagi P, et al. QT dispersion-an ignored screening tool for cardiovascular disease in diabetics. IOSR Journal of Dental and Medical Sciences 2017;16(3):11-13.

[16] Kumar R, Fisher M, Macfarlane PW. Diabetes and the QT interval: time for debate. The British Journal of Diabetes \& Vascular Disease 2004;4(3):146-50.

[17] Veglio M, Bruno G, Borra M, et al. Prevalence of increased QT interval duration and dispersion in type 2 diabetic patients and its relationship with coronary heart disease: a population-based cohort. Journal of Internal Medicine 2002;251(4):317-24.

[18] Sawicki PT, Meinhold J, Kiwitt S, et al. QT interval dispersion is an important predictor or mortality in NIDDM patients. Diabetes 1996;45(Suppl 2):128.

[19] Dekker JM, Feskens EJ, Schouten EG, et al. QTc duration is associated with levels of insulin and glucose tolerance: the Zutphen elderly study. Diabetes 1996;45(3):376-80.

[20] Cardoso CRL, Salles GF, Deccache W. QTc interval prolongation is a predictor of future strokes in patients with type 2 diabetes mellitus. Stroke 2003;34(9):218794.

[21] Timar R, Popescu S, Simu M, et al. QTc interval and insulin resistance in type 2 diabetes mellitus. European Scientific Journal 2013;9(12):70-77.

[22] Kannel WB. Lipids, diabetes and coronary heart disease: insights from the Framingham Study. American heart Journal 1985;110(5):1100-7.

[23] Porez G, Prawitt J, Gross B, et al. Bile acid receptors as targets for the treatment of dyslipidemia and cardiovascular disease Thematic Review Series: new lipid and lipoprotein targets for the treatment of cardiometabolic diseases. Journal of Lipid Research 2012;53(9):1723-37. 